An important problem in serological screening is the tendency for false positive results to arise owing to "sticky serum" or "cross reactivity." This problem with specificity can now be overcome by using such tests as the western blot or the polymerase chain reaction. In the study of Brennan and colleagues $2.5 \%$ of the 96720 blood donors initially were positive for HTLV-I; only 35 of those were positive on one of two enzyme linked immunosorbent assays (but not true positives) and only five were truly infected with HTLV-I. ${ }^{1}$ Of these five, four were white women with sexual contact as a risk factor, and one a drug misuser.

The authors argue that selective screening based solely on ethnic origins would not exclude HTLV-I infection. Additionally, they discuss the risks of blood borne HTLV-I infection and developing diseases against the costs of screening and counselling, as well as the cost per infection prevented and diseases contracted. Screening does not seem to be cost effective in Britain at present.

Nevertheless, the issues of what other countries are doing, consumer protection, and product liability make the decision to screen blood donors non-selectively extremely complex. The incidence of infection in Britain so far is too low and the incubation time too long to justify screening all blood samples. As far as product liability and consumer protection are concerned, achieving zero risk is impossible given the remote chance that a seronegative specimen may give a positive result on testing with the polymerase chain reaction and that testing every specimen in this way could be prohibitively expensive.

Meanwhile, the situation should be kept under regular review. Trends in seroprevalence may be more important indications for action than absolute values.

\section{A G DALGLEISH}

Head

Department of Cellular and Molecular Sciences,

Division of Oncology,

St George's Hospital Medical School,

London SW17 0RE

1 Brennan M, Runganga J, Barbara JAJ, Contreras M, Tedder RS, Garson JA, et al. Prevalence of antibodies to human $\mathrm{T}$ cell leukaemia/ymphoma virus in blood donors in north London. BMF 1993;307:1235-8.

2 Dalgleish AG, Weiss RA. Human retroviruses. In: Zuckerman A, Pattison J, Banatvala J, eds. Clinical virology. Chichester: John Wiley, 1990: 525-50.

3 Ohara Y, Iwasaki Y, Izumo S, Kobayashi I, Yoshiooka A. Search for human T-cell leukemia virus type 1 (HTLV-1) proviral sequences by polymerase chain reaction in the central nervous system tissue of HTLV-1-associated myelopathy. Arch Virol 1992;124:31-43.

4 Dalgleish AG. The immunology of retrovirus disease. In: Rudge P, ed. Baillière's clinical neurology neurological aspects of human retroviruses. London: Baillière Tindall, 1992:23-40.

5 Dalgleish AG, Matutes E, Richardson J, Cruickshank K, Newell A, Sinclair A, et al. HTLV-1 and tropical spastic paraparesis virus culture and serological responses. AIDS Research and Human Retroviruses 1988;4:475.

6 Richardson J, Edwards A, Cruickshank J, Rudge P, Dalgleish AG. In vivo cellular tropism of human T cell leukaemia type 1. I Virol 1990;64:5682.

7 Elovaara I, Koenig S, Brewah Y, Woods R, Lehky T, Jacobson S. High human T cell lymphotrophic virus type 1 (HTLV-1) specific precursor cytotoxic $T$ lymphocyte frequencies in patients with HTLV-1-associated neurological disease. $f$ Exp Med 1993;177:1567-73

8 Lunardi-Iskandar Y, Gessain A, Lam V, Gallo R. Abnormal in vitro proliferation and differentiation of $T$ cell colony-forming cells in patients with tropical spastic paraparesis/human T lymphocyte virus type 1 (HTLV-1)-associated myeloencephalopathy and healthy HTLV-1 carriers. 7 Exp Med 1993;177:741-50.

9 Parker CE, Daenke S, Nightingale S, Bangham CRM. Activated, HTLV-1-specific cytotoxic Tlymphocytes are found in healthy seropositives as well in patients with tropical spastic paraparesis. Virology 1992;188:628-36.

10 Hollsberg P, Wucherpfennig KW, Ausubel LJ, Calvo V, Bierer B, Hafler D. Characterization of HTLV-1 in vivo infected T cells clones II-2-independent growth of nontransformed T cells. fImmunol 1992;148:3256-63.

11 Ali A, Patterson S, Cruickshank K, Rudge P, Dalgleish AG, Knight SC. Dendritic cells infected in vitro with human T cell leukaemia/ymphoma virus type-1 (HTLV-1); enhanced lymphocytic proliferation and tropical spastic paraparesis. Clin Exp Immunol 1993;94:32-7.

12 Cruickshank JK, Richardson JH, Morgan OStC, Porter J, Klenerman P, Knight J, et al. Screening for prolonged seronegative incubation of HTLV-1 in British and Jamaican relatives of British patients with tropical spastic paraparesis. $B M \mathcal{F} 1990 ; 300: 300-4$.

\title{
Identifying hearing impairment in infants and young children
}

\author{
Universal screening at birth comes a step closer
}

Parents and professionals want problems in a child's development detected early, ${ }^{1}$ and the newborn examination is an important opportunity. Recent technological developments have produced screening methods that permit the identification of hearing impairment in babies soon after birth, yet the average age at referral to audiology services is close to 3 years in the United States. Recent British studies have shown some improvement in early identification, ${ }^{2}$ but it is still well below the recommendation of the Joint Committee on Infant Hearing that hearing impaired children should be identified and enrolled in rehabilitation programmes by the age of 6 months. $^{3}$

A recent conference of the National Institutes of Health has considered the issues and produced a consensus statement. ${ }^{4}$ The panel recommends universal screening for hearing impairment before three months of age. Because of the unique accessibility of almost all infants in postnatal wards the panel believes that all newborn infants, at both high and low risk, should have a hearing test before discharge from hospital. This raises several important issues, which have also been debated in Britain, ${ }^{45}$ but without clear agreement in favour of universal screening at birth.

Firstly, what are the advantages of early identification of hearing impairment and the consequences of late identification? It is axiomatic that severe hearing impairment affects the acquisition of speech and language, academic achievement, and social and emotional development. The literature is sparse, however, on the difference made by early detection. Teachers' ratings of the intelligibility of hearing impaired children vary with the age when hearing impairment is identified, ${ }^{6}$ and children whose impairment is detected early have some better language scores. ${ }^{7}$ But few of the children in these studies were detected at birth, and no substantial paper has yet been published showing additional benefit from the fitting of hearing aids and treatment in the first few months of life as envisaged by the National Institutes of Health. Convincing data on outcome are needed to justify the effort and expense of screening at birth.

Secondly, which children should be screened for hearing impairment and when should testing be done? Although universal screening at birth would be costly, attempts to target babies at risk (those admitted to neonatal units and those with facial dysmorphisms, a family history of congenital deafness, and congenital infection) identify only about half those with sensorineural hearing loss. ${ }^{3}$ The prevalence of sensorineural or mixed congenital hearing impairment in Britain is around $1 \cdot 1 / 1000$ whereas babies who have needed admission to neonatal units have a 10 -fold increase in risk. ${ }^{2}$ Screening each baby at risk costs about $£ 40,{ }^{8}$ and all neonatal units should introduce screening. For those not at risk a combination of the form for parents "Can your baby hear you?" and a well performed distraction test at 6 to 8 months provides a satisfactory alternative. ${ }^{10}$ Universal neonatal screening would be costly, and achieving complete coverage 
would be hard. The results of the trial of universal neonatal screening in the Wessex region (1993-6) should help to evaluate the benefits and difficulties of this strategy for a large population. Whatever the outcome, later testing will be needed for those children with acquired hearing loss, who account for $6-7 \%$ of all hearing impaired children at age $5 .^{2}$ Parental concern should always lead to diagnostic testing, and the school entry "sweep" test of hearing (a modified pure tone audiogram) should be performed."

The consensus statement discusses the advantages and disadvantages of the current methods of screening newborn infants. Auditory brainstem responses are highly sensitive, detecting nearly all children born with appreciable deficits, but some false positive results occur in babies with normal hearing. The testing needs scalp electrodes and trained staff and is time consuming. Transient evoked otoacoustic emissions are low intensity sounds produced by the inner ear, which can be measured with a sensitive microphone placed in the ear canal. The test for them is less invasive and can be performed in a shorter time than auditory brainstem responses, and staff can be trained more easily. It is also sensitive but has more false positive results than those obtained with tests of auditory brainstem responses, resulting in a heavy follow up workload and unnecessary parental anxiety. The consensus panel recommends that newborn screening of transient evoked otoacoustic emissions is performed, with those infants who fail going on to additional tests with auditory brainstem responses, but it does so without having the results of large population based studies showing that this strategy is practical, especially given the heavy workload placed on the follow up services.

The National Institutes of Health consensus will probably increase the pressure for universal neonatal screening in Britain. But before any model of screening is introduced two things are necessary: thorough evaluation in the context of our postnatal wards and neonatal units and the provision in each area of comprehensive audiological diagnostic and treatment services. Screening is of no value without facilities for follow up.

DAVID A CURNOCK Consultant paediatrician

Nottingham City Hospital NHS Trust, Nottingham NG5 1PB

1 Hall DMB. Health for all children. 2nd ed. Oxford: Oxford University Press, 1991.

2 Davis AC, Wood S. The epidemiology of childhood hearing impairment: factors relevant to planning of services. Br f Audiol 1992;26:77-91.

3 Joint Committee on Infant Hearing. 1990 position statement. Rockville, Maryland: American Speech-Language-Hearing Association, 1991;33(suppl 5):3-6.

4 National Institutes of Health. Early identification of hearing impairment in infants and young children Bethesda: National Institutes of Health, 1993.

5 Haggard MP, Hughes E. Screening children's hearing. London: HMSO, 1992.

6 Markides A. Age at fitting hearing aids and speech intelligibility. Br f Audiol 1986;20:165-8.

Ramkalawan T, Davis AC. The effects of hearing loss and age intervention on some language metrics in a population of young hearing-impaired children. Br 7 Audiol 1992;26:97-107.

Haggard MP. Screening children's hearing. Br f Audiol 1992;26:209-15.

9 McCormick B. Screening for hearing impairment in young children. London: Chapman and Hall, 1988.

10 McCormick B. Commentary on: Scanlan PE, Bamford JM. Early identification of hearing loss: screening and surveillance methods. Arch Dis Child 1990;65:484-5.

\section{p53: a gene for all tumours?}

\section{Provides profound insights into the basic molecular mechanisms of cancer}

Of all the dominantly acting oncogenes and recessive tumour suppressor genes, the p53 gene is by far the most frequently mutated in human cancers. ${ }^{1}$ Recent experiments have shown how these mutations affect the structure and function of this remarkable gene, which is emerging as one of the few truly central players in the tumorigenic process. ${ }^{2}$ The hope is that such experiments may eventually provide better treatments for many types of cancer.

The p53 gene, on chromosome 17p13.1, encodes a nuclear phosphoprotein of 393 amino acids, which acts as a transcription factor. Several domains of the sequence are extremely highly conserved between different species, and most of the point mutations observed in human cancers map to these regions. Somatic mutation of the p53 gene occurs at both alleles in $50-80 \%$ of spontaneous human cancers from a wide variety of histological types, but germline mutations of p53 also play a part in inherited predispositions to certain types of cancer. In the Li-Fraumeni syndrome, which is a rare, heritable condition, family members who are highly susceptible to a range of malignant cancers before their early $30 \mathrm{~s}$ inherit non-sense or missense mutations in one p53 allele. Cells from unaffected members do not carry any mutation. The inheritance of a single (recessive) mutation allows normal development but greatly increases the risk of cancer because only a single somatic mutation is required in any cell to reduce its genetic complement to homozygosity for loss of $\mathrm{p} 53$.

What is the function of $\mathrm{p} 53$ ? Transgenic mice lacking functional $\mathrm{p} 53$ genes develop normally (so $\mathrm{p} 53$ protein cannot be essential for life) but invariably develop cancers at 3-6 months, showing that $\mathrm{p} 53$ is a central control point for passage through the cell cycle. ${ }^{3}$ Similarly, in normal cells with DNA damaged by ultraviolet or $\gamma$ irradiation, progression though the cell cycle is blocked at G1 coincident with a sharp rise in the levels of p53 protein. During the subsequent arrest of growth, repair of DNA is completed before the cells proceed into S phase "in which their DNA is replicated." If, however, genomic damage is excessive the cell undergoes programmed cell death-apoptosis ${ }^{4}$ - which requires p53 protein. ${ }^{56}$ Cells expressing mutant p53 protein, however, do not pause in G1 but continue straight into $S$ phase before repair of DNA is complete. p53 protein has therefore been described as the "guardian of the genome" as it prevents entry into $S$ phase unless, or until, the genome has been purged of potentially damaging (that is, transforming) mutations. ${ }^{7}$ In addition, because many chemotherapeutic drugs kill tumour cells by inducing apoptosis, loss of p53 protein function may also directly decrease the cells' sensitivity to such cytotoxic agents, enhancing the clinically dangerous emergence of drug resistant populations of cancer cells. ${ }^{8}$

Other experiments have shown that $\mathrm{p} 53$ protein acts as a transcription factor in the nucleus controlling gene expression, whereas mutant p53 protein no longer binds DNA. ${ }^{2}$ At least some of the genes that $\mathrm{p} 53$ protein regulates may therefore promote repair of DNA or terminal cell differentiation, including apoptosis. ${ }^{1}$ Mutations of $\mathrm{p} 53$ protein would prevent the transcriptional activation of this array of cell protective genes, allowing the cell to progress unchecked through repeated cell divisions.

Mutations in p53 either prevent production of protein or generate mutant proteins that have lost their normal function. ${ }^{9}$ In addition to an inability to suppress cell division, many mutants express a gain of function which actively 